Cumhuriyet International Journal of Education-CIJE

e-ISSN: 2147-1606

Vol 5 (4), 2016, $16-30$

\title{
Examination of Decision Making Strategy and Scientific Literacy of University Students In Terms Of Different Variances
}

\author{
Esra KABATAŞ MEMİ̧, Rahşan BOZKURT, Esra CEVİZCİ, Felek AVUNÇ, Burcu \\ ÖĞRETMEN
}

Summary

\section{INTRODUCTION}

To understand and keep up with rapidly changing scientific knowledge and technological developments of our time, individuals have to be scientifically literate. Many countries realized the importance of scientific literacy (Turgut, 2007) have carried out reforms in education programs to educate scientifically literate individuals (DeBoer, 2000).Scientifically literate students are expected to acquire decision-making skills. The process of determining the correct thing to do in conflict situations is defined as strategic decision making (Ersever, 1996). There are many studies in the literature about decisionmaking strategies (Bağlıkol, 2010; Eldeleklioğlu, 1996; Temur, 2012) and scientific literacy, but there are scarcely any studies about the comparison of these variables in the same study group. In this context, the study examines the science literacy and decision-making strategies of classroom teachers studying at the University of Kastamonu during the 2014-2015 fall semester of the academic year, according to different variables (gender, age, and the level of the high school they graduated, the city they live in).

\section{METHOD}

In this study, to determine the science and technology literacy levels and decisionmaking skills of students a questionnaire (a survey scan method, which is detailed research model) is used. The study group is composed of students studying in Kastamonu University Faculty of Education, Science Teaching (186 students) and Class Education (322 students) Departments (studying in 1, 2, 3 and 4. classes) during the 2014-2015 fall semester. In total 508 students (379 women and 129 men) were included in the study. The data collection tools were an information form developed by the researchers, "Science and Technology Literacy Levels Scale" and "Decision Making Strategies Scale". To determine the science literacy level of teacher candidates, a 16 article triple-point Likert-type scale was used. Science and Technology Literacy Scale has been developed by Collete, Chiappetta, and Hurd and has been translated by Çepni, Ayvac1, and Bacanak in 2016.The Cronbach alpha value of science and technology literacy level scale is .81 .

To determine the variables that affect the decisions of the working group, Decision Making Strategies Scale developed by Kuzgun (1993) which is composed of 40 validated and reliable articles was used. A Likert-type scale composed of "never, sometimes, often and always" expressions was used. The Cronbach alpha value of the decision-making strategies scale is calculated as .73.

\section{RESULTS}

\section{Decision-making skills}

The only determined variable that affects decision-making skills are class level. To determine whether class level effect decision-making skills, a one-way ANOVA test is used. According to the results of the one-way ANOVA test, the class level significantly affects decision making $(\mathrm{F}(3,508)=5,818, \mathrm{p}=.001)$. To determine which groups differ, a post-hoc test, 
LSD was conducted. According to the test results, decision making skills of second-year students $(X=106.81, S D=8.38)$, third-year students $(X=106.82, S D=8.25)$ and fourth grade students $(X=107.72, S D=7.81)$ are more improved that freshmen $(X=103.68, S D=7.79)$.

\section{Science literacy levels}

A one-way ANOVA test was applied to determine whether the class level of participating students (1., 2., 3. and 4. class) effect the science literacy levels. One-way ANOVA test results are given in Table 12. According to the results, class level appears to have a significant effect on science literacy $(\mathrm{F}(3,504)=3.181, \mathrm{p}=.024)$.A post hoc test (LSD) was conducted to determine which groups differ. According to the results, statistically significant differences between the science literacy scores of third-grade students $(X=22: 46, S D=4.39)$ and the fourth-grade students $(X=24.14, S D=4.80)$ for the fourth grade students. Similarly, there is a statistically significant difference between the science literacy scores of second-grade students $(X=24.39, \mathrm{SD}=5.25)$ and third-grade students $(X=22: 46, \mathrm{SD}=4.39)$ for the secondgrade students.

When the departments of the students are considered, a t-test on science literacy scores (independent sample t-test) was performed. Results show that the department students study has a significant effect on the decision-making skills of the students, for classroom teaching students (t 506 $=-3.76, \mathrm{p}=.000)$.

\section{The relationship between decision-making and scientific literacy}

To determine the relationship between the scores students received from the decisionmaking scale and science literacy scale, Pearson correlation value was analyzed. The results show that the scores taken from both scales create a negative relationship $(r=-.165)$.So, as the decision-making skill scores of the students increase, science literacy scores also decrease. This may be considered a surprising result.

\section{DISCUSSION AND CONCLUSION}

Results show that gender, secondary education institution graduated, the number of siblings and the profession of the parents have no effect on the scores teacher candidates take according to the scales. The department they study have no effect on the decision-making skills of the students but constitutes the significant difference between the levels of science literacy. Furthermore, according to class levels, there is a statistically significant difference between science literacy levels and decision-making skills. Analysis of the results show that; there is an important difference between third and fourth classes for the fourth-grade classes and between third and second-grade classes for the second-grade classes. There a significant difference in decision-making skills between first, second and third fourth grade classes to the detriment of first-grade classes.

In their studies, Yetişir and Kaptan (2008) found that the difference is for the fourthgrade classes. Yakar (2010) states that the education provided is essential for improving the scientific literacy. Bacanak (2002), indicates that it is a paradoxical situation that even though the "knowing and understanding" levels of last year students is high, the level of values and attitudes towards science and technology is low. This situation is similar to the results of our work.

As it is stated in the Science and Technology curriculum (MOE, 2006) scientifically literate individuals are expected to have the ability to take effective decisions. Science literacy and decision-making are closely related concepts as it is widely mentioned in the literature. It is stated in the literature that scientifically literate individuals are problem solvers and skilled in decision-making when associating problems. It is surprising that this study revealed a significant negative relationship between science literacy and decision-making skills. This point has to be investigated in detail in following studies. 